\title{
Structural Analysis of Motorcycle Alloy Wheel
}

\author{
Navuri Karteek $^{1 *}$, Pothamsetty Kasi V Rao ${ }^{2}, K$. Ravi Prakash Babu ${ }^{3}$, D. Mojeshwara Rao ${ }^{4}$ \\ ${ }^{1}$ Research Scholar, Department of Mechanical Engineering, Andhra University, Vishakapatnam, A.P., India \\ ${ }^{2}$ Department of Mechanical Engineering, Koneru Lakshmaiah Education Foundation, Vaddeswaram, A.P., India \\ ${ }^{3}$ Department of Mechanical Engineering, Prasad V. Potluri Siddhartha Institute of Technology, Kanuru, Vijayawada, A.P, India \\ ${ }^{4}$ Department of Mechanical Engineering, Narasaraopeta Engineering College, Guntur, A.P., India
}

\begin{abstract}
Alloy wheels in the motor cycle play major role to carry the load over the spoke wheels. The shape and orientation of the spokes are responsible for withstand the loads which are acting on the alloy wheel rim and hub bearing surface. These alloy wheel spokes are subjected to different types of loads i.e., radial loads, impact load, bending load, torsion load and maximum deflection load. So it is necessary to study the response of the wheel under these types of loads before the product going into the market. In the present article 4 models of motor cycle alloy wheel are modeled based on the dimensions in the reference article. The material chosen for the analysis of the alloy wheel is aluminum alloy which is homogenous in nature having isotropic properties. The magnitude of the five different loading conditions and boundary conditions are taken from the Automotive Industry Standards (AIS). The four models of alloy wheels are analyzed under radial, impact, bending, torsion and maximum deflection loads cases by using by using ANSYS workbench. The results show that all four models are having enough fatigue life, strength and stiffness against the different loading conditions.
\end{abstract}

\section{INTRODUCTION}

Alloy wheel exhibits several advantages over the spoke wheel of the motor cycle. In different conditions these alloy wheels are fails due to insufficient strength and stiffness. In radial load condition, the maximum design load is acts like half sine wave load distribution on the rim surface of the Alloy wheel upon $140^{\circ}$ contact angle with road. In Impact load condition the load is applied from a certain height to check whether the alloy wheel can withstand the impact force which is result from the speed breakers, etc. In bending load condition, bending moment is calculated upon the automotive industry standards and it is applied on the hub bearing surface to check the alloy wheel whether it is having enough life cycles upon the bending loads. In torsion load case, the torsion is calculated from the AIS and it is applied on the wheel hub bearing surface to check the alloy wheel life cycles under torsion load which is results from the motion of the vehicle. In maximum deflection load condition, the applied load is calculated from the AIS and it is applied on the Alloy wheel hub surface to check whether the alloy wheel is having enough stiffness to withstand the load. The selection of material also plays a major role to with stand the loads in various conditions. In present days all the automobile industries are using aluminum alloy and magnesium alloy.
Navuri Karteek [1] perform static and fatigue analysis on different alloy wheel models. He concluded four alloy wheels models out of all having better fatigue life, less damage and better factor of safety under different materials. Shantaram

Jadhav [2] performed different loading analysis on the spoke alloy and calculated the life, stresses and deformations. He concluded the spoke wheel is having better life cycles, strength and stiffness against the loads. Later he validated the FEM results with practical results. Sahil Bandral [3] performed impact analysis on the four wheeler alloy wheel and calculated the stresses by varying the number of spokes. He concluded 3 spoke alloy wheel shows better results. Anusha R [4] performed static and impact analysis on the four wheeler alloy wheel and calculated the stresses and deformations. Later performed weight optimization and reduced the weight by $20 \%$. Shwetabh Suman [5] performed impact and modal analysis for different alloy wheel compositions. Results shows alloy wheel with Ti-13 material having less natural frequencies in modal analysis and alloy wheel with Mg-AZ31B material having less deformations in impact analysis. G. V. R Seshagiri rao [6] performed impact analysis on the aluminum alloy wheel and calculated induced stresses. The results show that life of the alloy wheel is maximum at hub and minimum at the rim surface. A Eswara Kumar [7] performed static and modal analysis on the different types of alloy wheel and calculated the results. The

\footnotetext{
${ }^{*}$ Corresponding author: karteeknavuri@gmail.com
} 
results shows that 3 spoke alloy wheel plays better performance in static analysis, while 5 spoke alloy plays better performance in modal analysis.

\section{PROCEDURE}

\subsection{Problem Statement}

To study the life, strength and stiffness of the four different alloy wheel models subjected to variable pressure, impact load, bending load, torsion load and maximum deflection load. The material chosen is aluminum alloy which is homogenous in nature and having isotropic properties.

\subsection{Geometry}

The models of the alloy wheel are selected from the research article [1]. As per the dimensions mentioned in the article, four type alloy wheels are designed. The designed alloy wheels are shown in the below figure.
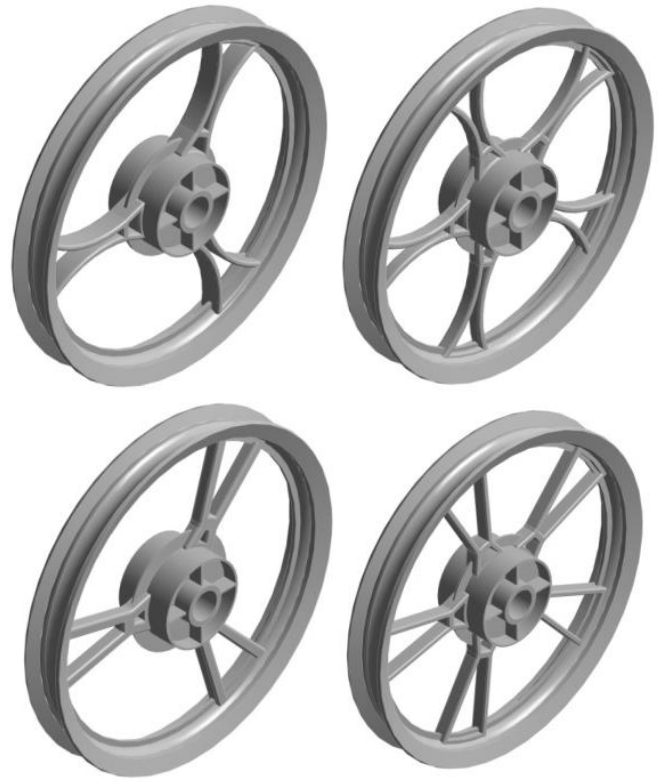

Figure 1 Different alloy wheels

\subsection{Coordinate System}

Cylindrical coordinate system is assigned to the alloy wheel for applying radial load on the rim surface. The cylindrical coordinate system which is assigned to the alloy wheel are shown in the below figure.

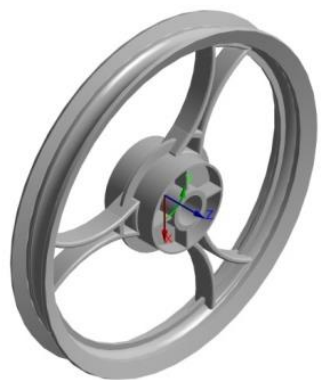

Figure 2. Cylindrical coordinate system of the alloy wheel

\subsection{Mesh}

Meshing is the process of converting the geometry entities of the alloy wheel in to finite element entities. Proper meshing is done for force and reaction convergence. 8 node hexahedron and 5 node tetrahedron elements are used for meshing operation with a element size of $10 \mathrm{~mm}$. The finite element models of the four different alloy wheels are shown in the below figure. 3 .
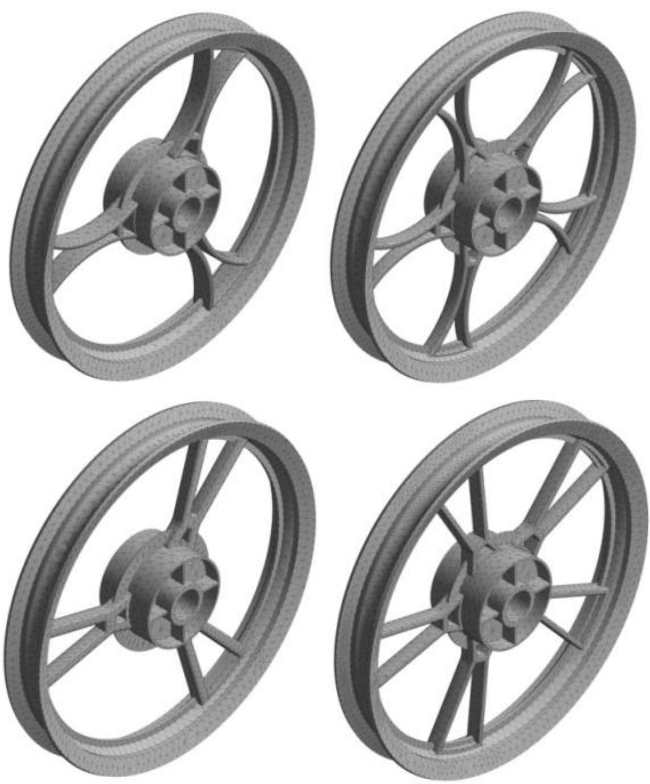

Figure 3. Mesh of the four different Alloy Wheels

\subsection{Loads}

The calculations of loads which are applied on the alloy wheel in different cases are discussed below.

Variable Radial Pressure

The variable radial pressure which is applied on the wheel rim surface for 1400 in half sine wave is discussed below. Average weight of the bike $=181 \mathrm{~kg}$

Extra load $=20 \mathrm{~kg}$

Average weight of the first person $=70 \mathrm{~kg}$

Average weight of the second person $=70 \mathrm{~kg}$

Total mass $=341 \mathrm{~kg}$

Force $=$ mass $*$ gravity

$\mathrm{F}=341 \times 9.81$

$\mathrm{F}=3345.21 \mathrm{~N}$

Due to the tyre, only $70 \%$ of the load is transmitted to alloy wheel.

$\mathrm{F}_{\mathrm{Net}}=0.7 \times 3345.21=2341.647 \mathrm{~N}$

The net force is assumed to apply on the single tyre.

Here the force is converted in to pressure.

Static $\operatorname{radial}$ load $(\mathrm{Q})=\mathrm{K} \times \mathrm{W}$

$\mathrm{Q}=$ Static Radial Load

$\mathrm{K}=$ Constant related to Industrial Standards

$\mathrm{K}=2.25$

$\mathrm{W}=$ Maximum Design Load $=2341.647 \mathrm{~N}$

$\mathrm{Q}=2.25 \times 2341.647$

$$
\mathrm{Q}=5268.7057 \mathrm{~N}
$$


The surface area of the rim surface to $140^{\circ}=$ $40694 \mathrm{~mm}^{2}$

$$
\begin{aligned}
\text { Pr essure } & =\frac{\text { Force }}{\text { Surface_Area }}=\frac{5268.7057}{40694} \\
& =0.1294 \mathrm{~N} / \mathrm{mm}^{2} \text { or MPa. }
\end{aligned}
$$

Here the load is applied in variable form and it is assigned in a function form.

$$
\text { Load }=\text { Pressure } x \operatorname{Sin} \theta
$$

The load is applied as half sine distribution over the contact angle of 1400 on the wheel rim of the four alloy wheel models. The calculated and applied half sine distribution load on the wheel is shown in the below figure 4 . The applied load on the alloy wheel is shown in the below figure 5.0 .

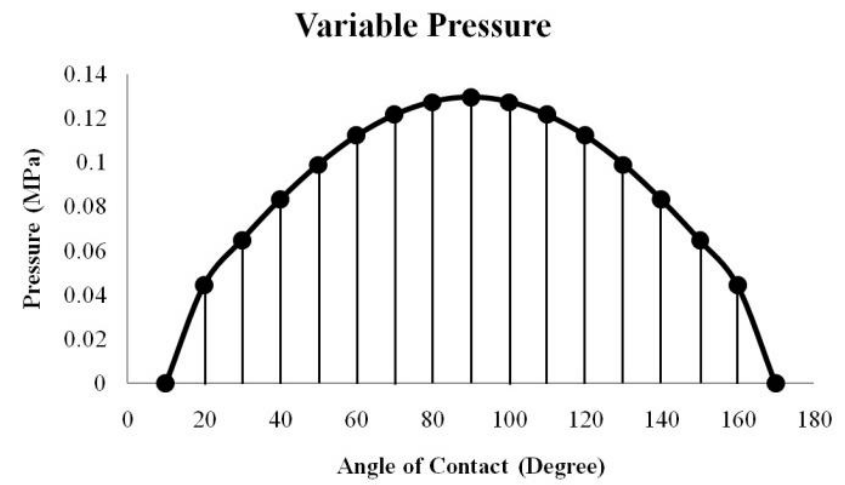

Figure 4. Half Sine Distribution Load

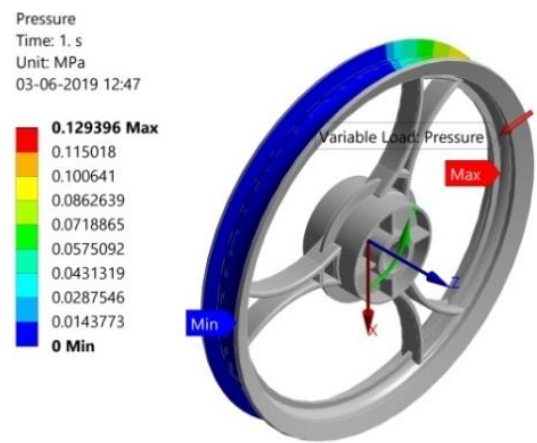

Figure 5 Applied load on Alloy Wheel

Impact Load

The Impact load which is applied from a height of 230 $\mathrm{mm}$ height is converted in to the impact force. The impact force is applied on the 50 contact surface of wheel rim. The impact force calculation is discussed below.

Impact load (total mass of striker) is calculated by the following equation

$\mathrm{m}_{1}+\mathrm{m}_{2}=\frac{K W}{g}$

$\mathrm{m}_{1}=$ Mass of the main striker

$\mathrm{m}_{2}=$ Mass of the Auxiliary weight $=40 \mathrm{~kg}$

$\mathrm{W}=$ Maximum design load $=2341.647 \mathrm{~N}$

$\mathrm{K}=$ Impact Constant depends on the Industry $=1.5$

$\mathrm{g}=9.81 \mathrm{~m} / \mathrm{s}^{2}$

$$
\begin{gathered}
\mathrm{M}_{1}+40=\frac{1.5 * 2341.647}{9.81} \\
\mathrm{M}_{1}+40=358.05 \mathrm{~kg}
\end{gathered}
$$

$$
\mathrm{M}_{1}=318.05 \mathrm{~kg}
$$

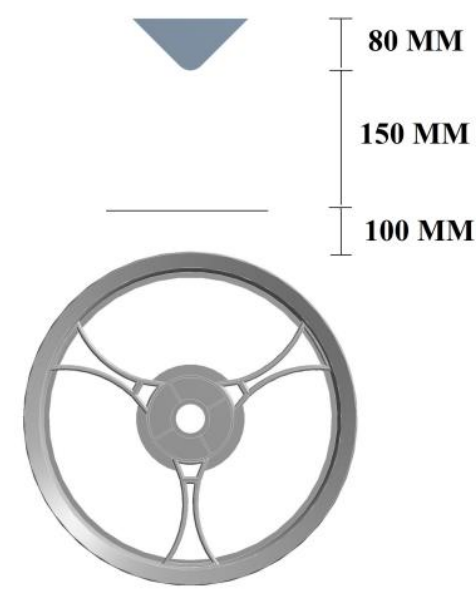

Figure 6. Impact Setup for Alloy wheel

$$
\begin{aligned}
& \text { At height } 230 \mathrm{~mm} \\
& \text { Potential Energy }=\mathrm{m} \mathrm{g} \mathrm{h} \\
& \text { Kinetic Energy }=0.5 \mathrm{~m} \mathrm{v}^{2} \\
& \qquad \begin{array}{r}
\text { Impact Velocity }=\mathrm{v}^{2}-\mathrm{u}^{2}=2 \mathrm{gh} \\
\mathrm{v}^{2}=2 \mathrm{gh} \\
v=\sqrt{2 g h} \\
v=\sqrt{2 * 9.81 * 0.23} \\
\mathrm{v}=2.1242 \mathrm{~m} / \mathrm{s}^{2}
\end{array}
\end{aligned}
$$

Initial Potential Energy $=$ Final Kinetic Energy

$$
\begin{gathered}
\mathrm{mgh}=0.5 \mathrm{~m} \mathrm{v}^{2} \\
\mathrm{mah}=0.5 \mathrm{~m} \mathrm{v}^{2} \\
\mathrm{f} \mathrm{h}=0.5 \mathrm{~m} \mathrm{v}^{2} \\
\mathrm{f}_{\text {avg }}=\frac{0.5 * m v^{2}}{h}
\end{gathered}
$$

$\mathrm{h}=$ Depth of penetration

Depth of penetration assumed to be thickness of the tyre.

$$
\begin{aligned}
\mathrm{h}=100 \mathrm{~mm}= & 0.1 \mathrm{~m} \\
\mathrm{f}_{\mathrm{avg}} & =\frac{0.5 * 358.05 * 4.5126}{0.1}
\end{aligned}
$$$$
\mathrm{f}_{\text {avg }}=8078.68 .68 \mathrm{~N}
$$

$30 \%$ of load is assumed to be eliminated by the tyre.

$$
\mathrm{f}_{\text {avg }}=5655.076 \mathrm{~N}
$$

Surface area of $5^{0}=1453 \mathrm{~mm}^{2}$

$$
\mathrm{P}=\frac{f}{A}=3.892 \mathrm{~N} / \mathrm{mm}^{2} \text { or } \mathrm{MPa}
$$

Here the load is applied in the form of pressure on 50 surface area of the rim of alloy wheel. The applied pressure on the alloy wheel is shown in the below figure 


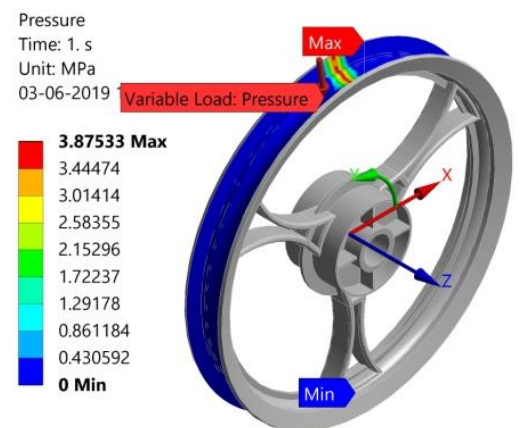

Figure 7. Impact Load on Alloy Wheel

Bending Load

The calculation of bending load which is applied on the wheel hub bearing surface is discussed below.

Bending moment $(\mathrm{M})=\mathrm{Sm} \cdot \mu . \mathrm{W} . \mathrm{r}$

$\mathrm{Sm}=$ Bending Co-efficient $=0.7$

$\mu=$ Coefficient of friction $=0.7$

$\mathrm{W}=$ Design Load $=2341.647 \mathrm{~N}$

$\mathrm{r}=$ Maximum static loaded radius

$\mathrm{r}=250 \mathrm{~mm}$

$\mathrm{r}=0.25 \mathrm{~m}$

$\mathrm{M}=0.7 \times 0.7 \times 2341.647 \times 0.25$

$\mathrm{M}=286.85 \mathrm{Nm}$

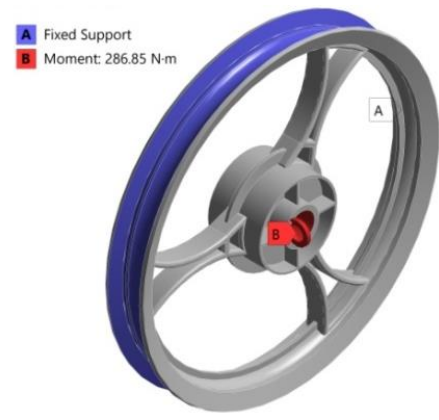

Figure 8. Bending Load on Alloy Wheel

Torsion Load

The calculation of torsion load which is applied on the wheel hub bearing surface is discussed below.

$\mathrm{T}= \pm \mathrm{W} \mathrm{r}$

+ indicates forward torsion

- Indicates backward torsion

$\mathrm{W}=$ Maximum Design load $=2341.647 \mathrm{~N}$

$\mathrm{r}=$ Maximum static loaded radius $=250 \mathrm{~mm}=0.25$

$\mathrm{m}$

$\mathrm{T}=2341.647 \times 0.25$

$\mathrm{T}=585.4117 \mathrm{Nm}$

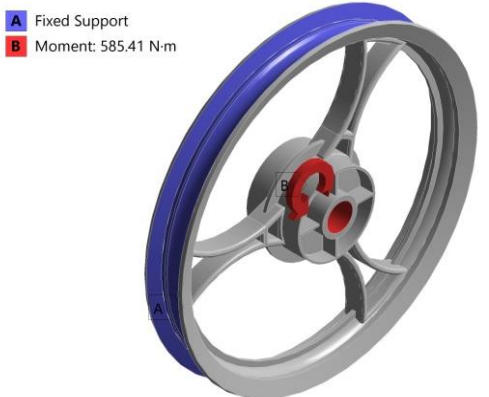

Figure 9. Torsion Load on Alloy Wheel

Maximum Deflection load

The magnitude of maximum deflection load is selected from the AIS-073-Part 3. The maximum load related to the Nominal rim width are listed in the below table 1.0. Nominal Rim Width $=2.15$ inch

Selecting the proper magnitude of the force from the below table 1.0 with related to nominal rim width.

Table 1. Magnitude of the force related to nominal diameter

\begin{tabular}{|c|c|c|}
\hline \multicolumn{2}{|c|}{ Nominal rim width (inch) } & Load kN (kgf) \\
\hline 1.1 & & $0.98(100)$ \\
\hline 1.2 & & $1.47(150)$ \\
\hline 1.4 & & $1.96(200)$ \\
\hline 1.5 & & $2.45(250)$ \\
\hline 1.6 & & $3.43(350)$ \\
\hline 1.85 & MT 1.85 & $4.41(450)$ \\
\hline 2.15 & MT 2.15 & $4.90(500)$ \\
\hline 2.5 & MT 2.50 & $6.37(650)$ \\
\hline 2.75 & MT 2.75 & $6.37(650)$ \\
\hline & MT 3.00 & $6.37(650)$ \\
\hline & MT 3.50 & $6.37(650)$ \\
\hline & MT 4.00 & $6.37(650)$ \\
\hline & MT 4.50 & $6.37(650)$ \\
\hline & MT 5.00 & $6.37(650)$ \\
\hline & MT 5.50 & $6.37(650)$ \\
\hline & MT 6.00 & $6.37(650)$ \\
\hline
\end{tabular}

From the above table, force is taken as $4.9 \mathrm{KN}(4900 \mathrm{~N})$ for respective nominal rim width.

The force which is selected from the above table 1.0 is converted to the pressure.

$$
\begin{gathered}
\text { Pressure }=\frac{\text { Force }}{\text { Surface_Area }}=\frac{4900}{1453.335} \\
=3.3715 \mathrm{MPa}
\end{gathered}
$$

The calculated pressure is applied on the 50 contact angle of alloy wheel rim surface.

The limit of the maximum deflection due to the applied force on the wheel rim surface is listed in the below table 2.0 
Table 2. Maximum deflection limits

\begin{tabular}{|l|c|c|c|}
\hline & \multicolumn{3}{|c|}{ Nominal rim diameter code (inch) } \\
\hline & 15 or less & $16,17,18$ & 19 or more \\
\hline Deflection $(\mathrm{mm})$ & 10 & 15 & 20 \\
\hline
\end{tabular}

The Nominal Rim Diameter of the wheel rim is 6.6304 inch. So the maximum deflection of the alloy wheel should not exceed $15 \mathrm{~mm}$ in safe case. The applied load on the wheel rim surface is shown in the below figure 10.0.

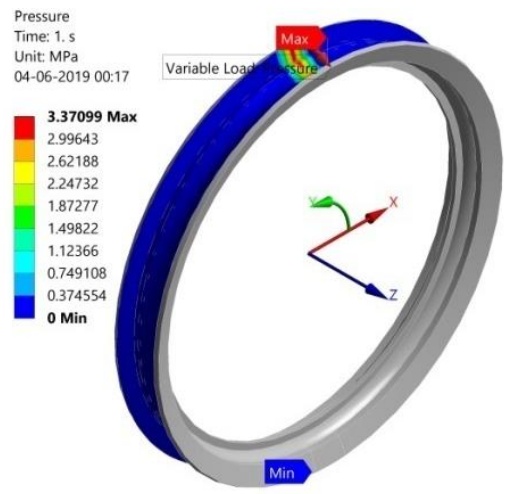

Figure 10. Maximum Deflection Load on Alloy Wheel

\subsection{Supports}

In the radial pressure \& impact load case, the boundary conditions are given to the rim surface of the alloy wheel in form of cylindrical support. Linear movements in 2 directions are arrested and free to rotate. The boundary conditions of the alloy wheel in radial pressure and impact load case are shown in the below figure 11.0.

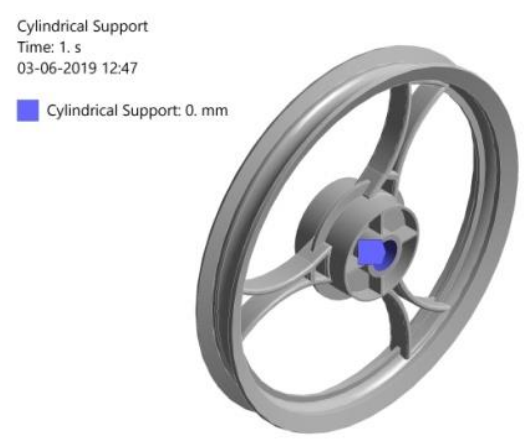

Figure 11. Cylindrical Support for Radial \& Impact load case

In the bending \& torsion load case the boundary conditions are applied to the bearing surface of the hub in the form of fixed support. The Linear movements surface of the hub are arrested in all directions. The boundary conditions of the alloy wheel in torsion and bending load case is shown in the below figure 12.0.

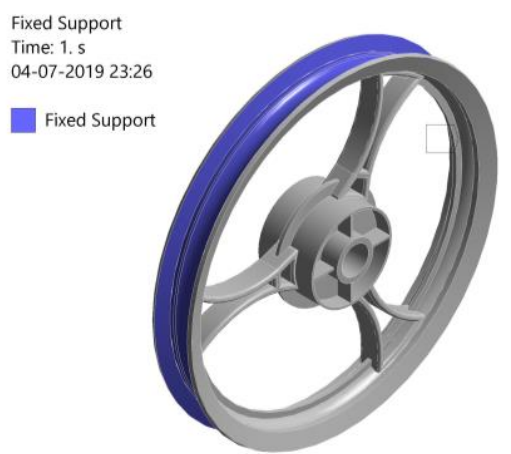

Figure 12. Fixed Support for Bending \& Torsion load case

In the maximum deflection load case the boundary conditions are applied to the lower surface of the whel rim for $5^{0}$ contact angle as fixed support. The Linear movements surface of the rim are arrested in all directions. The boundary conditions of the alloy wheel in maximum deflection load case is shown in the below figure 13.0.

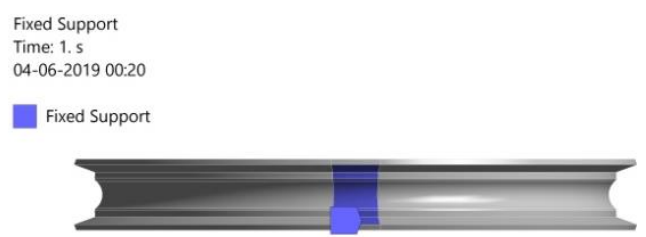

Figure 13. Fixed Support for Maximum Deflection load case

\subsection{Material}

The material selected for the alloy wheel is aluminum alloy which is homogenous in nature and having isotropic properties. The elements which are present in the aluminum alloy are listed in the below table 3.0

Table 3. Elements of Aluminum Alloy

\begin{tabular}{|l|l|}
\hline Material Name & \multicolumn{1}{|c|}{ Elements } \\
\hline Aluminum Alloy & $\begin{array}{l}\text { Copper, Magnesium, Manganese, Silicon, } \\
\text { Tin and Zinc. }\end{array}$ \\
\hline
\end{tabular}

The mechanical properties of Aluminium Alloy are listed in the below table 4.0

Table 4. Properties of Aluminium Alloy

\begin{tabular}{|c|c|c|c|c|}
\hline & $\begin{array}{c}\text { Young's } \\
\text { Modulus } \\
(\mathrm{MPa})\end{array}$ & $\begin{array}{c}\text { Density } \\
\left(\mathrm{kg} / \mathrm{m}^{3}\right)\end{array}$ & $\begin{array}{c}\text { Poisson's } \\
\text { Ratio }\end{array}$ & $\begin{array}{c}\text { Tensile } \\
\text { Yield } \\
\text { Strength } \\
(\mathrm{MPa})\end{array}$ \\
\hline $\begin{array}{c}\text { Aluminium } \\
\text { Alloy }\end{array}$ & 71000 & 2770 & 0.33 & 280 \\
\hline
\end{tabular}

The fatigue properties of aluminium alloy is attained from the axial bending fatigue test under fully reversed loading having R-Ratio $=-1$. The fatigue properties of the aluminium alloy are listed in the below table 5.0

Table 5. Fatigue Properties of Aluminium Alloy

\begin{tabular}{|l|c|}
\hline Cycles & $\begin{array}{c}\text { Alternating Stress } \\
\text { (MPa) }\end{array}$ \\
\hline 1700 & 275.8 \\
\hline 5000 & 241.3 \\
\hline 34000 & 206.8 \\
\hline
\end{tabular}




\begin{tabular}{|l|l|}
\hline 140000 & 172.4 \\
\hline 800000 & 137.9 \\
\hline 2400000 & 117.2 \\
\hline 55000000 & 89.63 \\
\hline 100000000 & 82.74 \\
\hline
\end{tabular}

From the above table, it is noticed that endurance limit of the aluminium alloy is $82.74 \mathrm{MPa}$. If the alternating stress of Alloy wheel is less than the endurance limit of the material, structure of alloy wheel experience infinite life.

To calculate the life of the structure under a particular stress value, the below calculations are made under Log-Log interpolation method.

$$
\begin{gathered}
\log \sigma=\mathrm{A} \log \mathrm{N}+\mathrm{B} \\
\sigma_{1}=275.8 \mathrm{MPa} \& \mathbf{N}_{\mathbf{1}}=1700 \text { Cycles } \\
\sigma_{2}=82.74 \mathrm{MPa} \& \mathbf{N}_{2}=100000000 \text { Cycles } \\
\log (275.8)=\mathrm{A} \log 1700+\mathrm{B} \\
\log (82.74)=\mathrm{A} \log 100000000+\mathrm{B} \\
2.4406=3.2304 \mathrm{~A}+\mathrm{B} \\
1.9177=8 \mathrm{~A}+\mathrm{B}
\end{gathered}
$$

By solving the above two equations

$$
\begin{aligned}
& A=-0.1096 \\
& B=2.79475
\end{aligned}
$$

\section{RESULTS \& Discussions}

\section{Radial Load Case}

In the radial load case, the alloy wheel should sustain the load before $5+10^{\wedge} 5$ life cycles. The calculated von-mises stress of the four different alloy wheels are shown in the below figures.

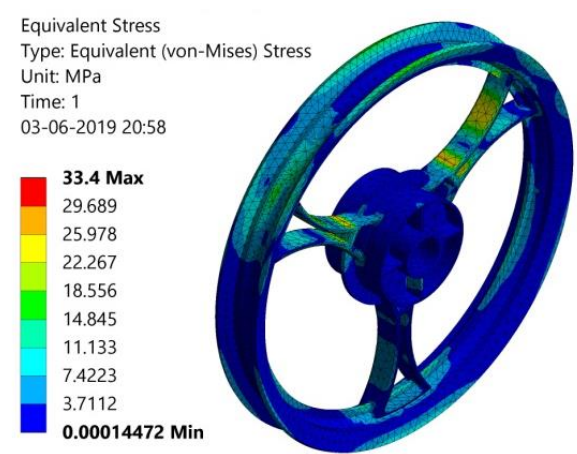

Figure. 14. Vonmises Stresses for Model 1 under Radial load case

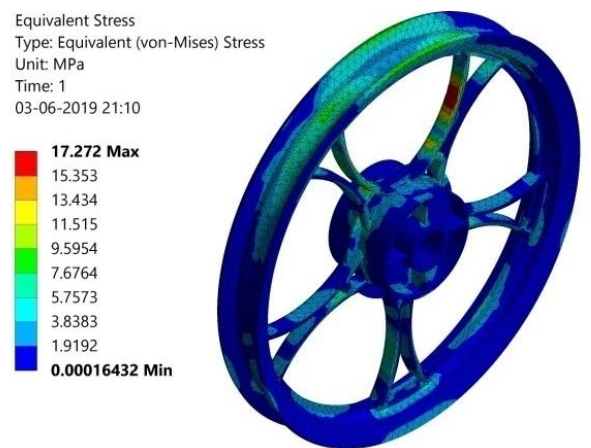

Figure. 15. Vonmises Stresses for Model 2 under Radial load case

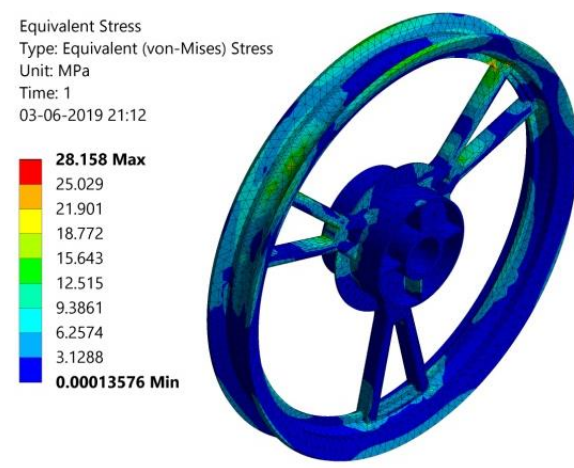

Figure. 16. Vonmises Stresses for Model 3 under Radial load case

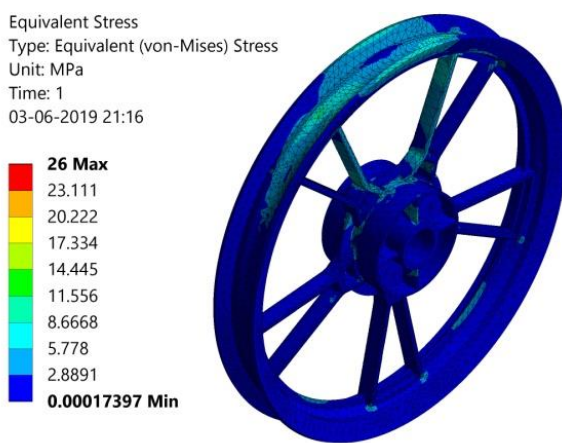

Figure. 17. Vonmises Stresses for Model 4 under Radial load case

From the above figures, the maximum stress value of the four different alloy wheel models is $33.4 \mathrm{MPa}$ developed in the model 1. It clearly shows that stress values of the four different alloy wheels are below the endurance limit [82.74 $\mathrm{MPa}$ ] of the material. So the four different alloy wheels experience the infinite life cycles.

Impact Load Case

In the impact load case, the stresses induced in the alloy wheel should be below the yield strength of the material. The calculated von-mises stress of the four different alloy wheels are shown in the below figures.

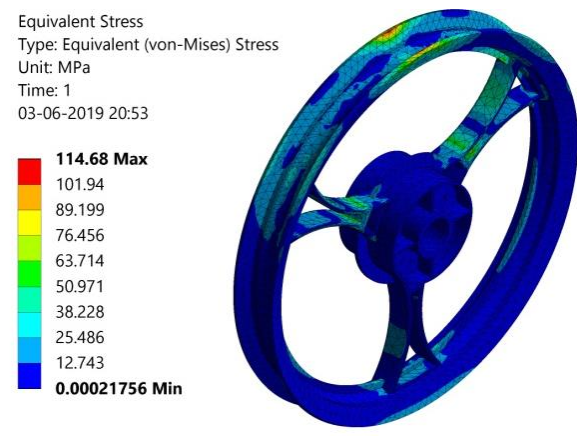

Figure. 18. Vonmises Stresses for Model 1 under impat load case 


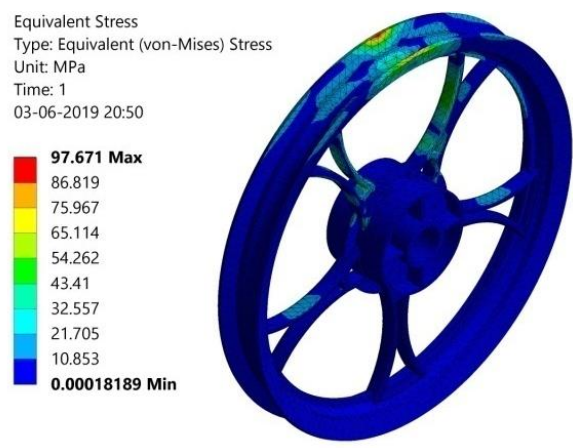

Figure. 19. Vonmises Stresses for Model 2 under impat load case

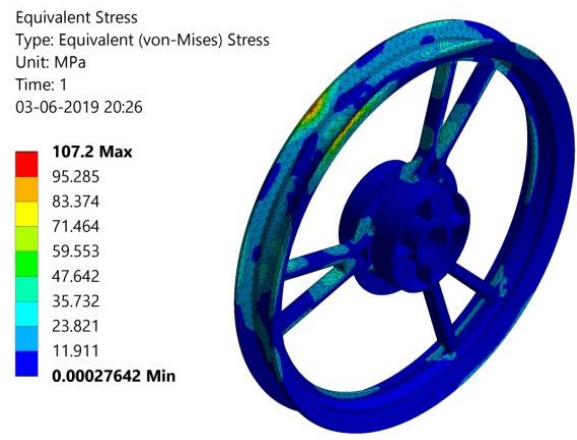

Figure. 20. Vonmises Stresses for Model 3 under impat load case

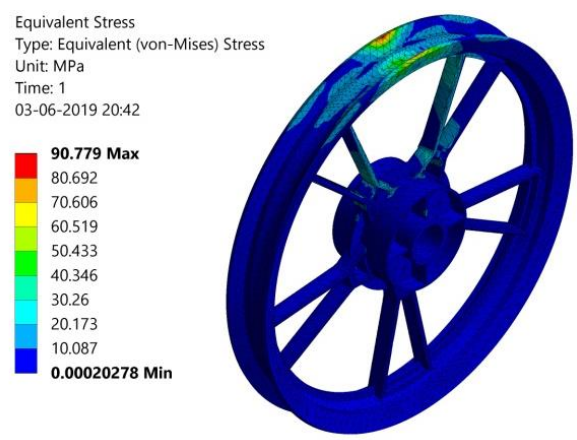

Figure. 21. Vonmises Stresses for Model 4 under impat load case

From the above figures, the maximum stress value of the four different alloy wheel models is $114.68 \mathrm{MPa}$ developed in the model 1 . It clearly shows that stress values of the four different alloy wheels are below the yield strength [280 MPa] of the material. So the four different alloy wheel models are safe in strength point of view.

Bending Load Case

In the bending load case, the alloy wheel should sustain the load before 100000 life cycles. The calculated von-mises stress of the four different alloy wheels are shown in the below figures.

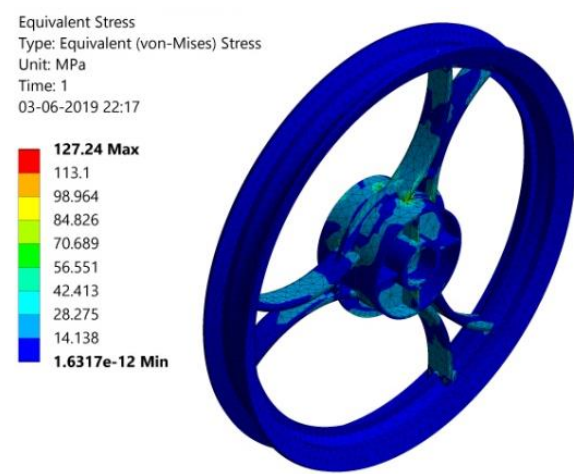

Figure. 22. Vonmises Stresses for Model 1 under bending load case

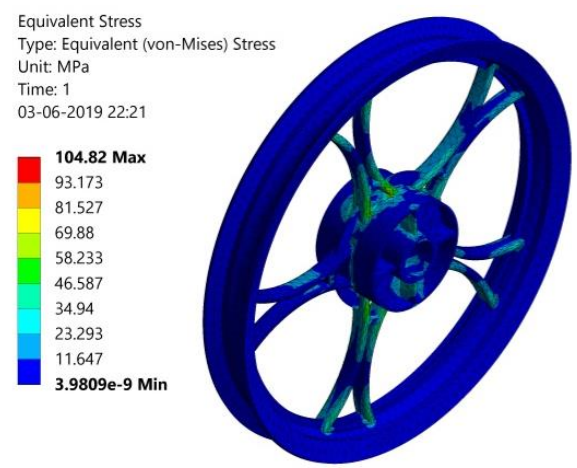

Figure. 23. Vonmises Stresses for Model 2 under bending load case

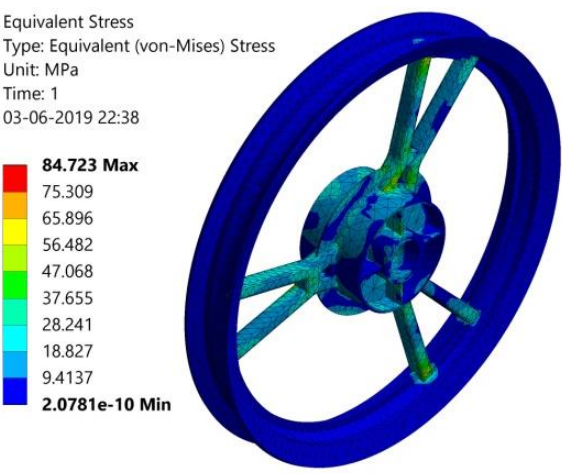

Figure. 24. Vonmises Stresses for Model 3 under bending load case

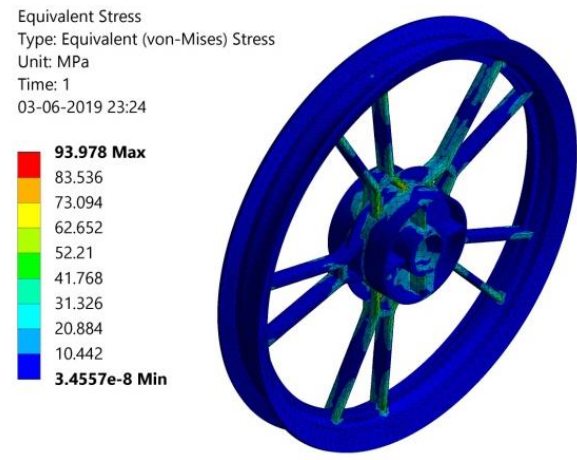

Figure. 25. Vonmises Stresses for Model 4 under bending load case

From the above figures, the maximum stress value of the four different alloy wheel models is $127.24 \mathrm{MPa}$ developed in the model 1.

The loading type is fully reversed type load which having zero mean stress effect. Therefore alternating stress amplitude is directly proportional to the alternating stress. 
The life cycles of the model 1 is calculated from the below equation.

$$
\begin{gathered}
\log \sigma=\mathrm{A} \log \mathrm{N}+\mathrm{B} \\
\log 127.24=-0.1096 \log \mathrm{N}+2.79475 \\
2.1046=-0.1096 \log \mathrm{N}+2.79475 \\
2.1046-2.79475=-0.1096 \log \mathrm{N} \\
-0.6901=-0.1096 \log \mathrm{N} \\
6.2965=\log \mathrm{N} \\
\mathrm{N}=1979396 \text { Cycles }
\end{gathered}
$$

It clearly shows that the life cycle of the model 1 greater than the 100000 cycles. It implies the remaining models which are below the stress value of model 1 are also experience more than 100000 life cycles.

\section{Torsion Load Case}

In the torsion load case, the alloy wheel should sustain the load before 100000 life cycles. The calculated von-mises stress of the four different alloy wheels are shown in the below figures.

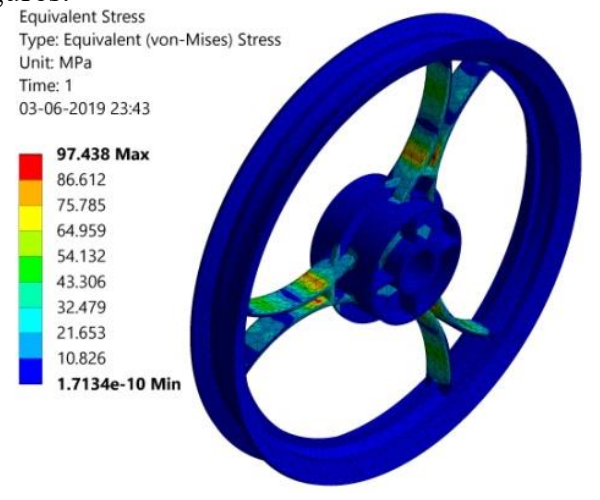

Figure. 26. Vonmises Stresses for Model 1 under torsion load case

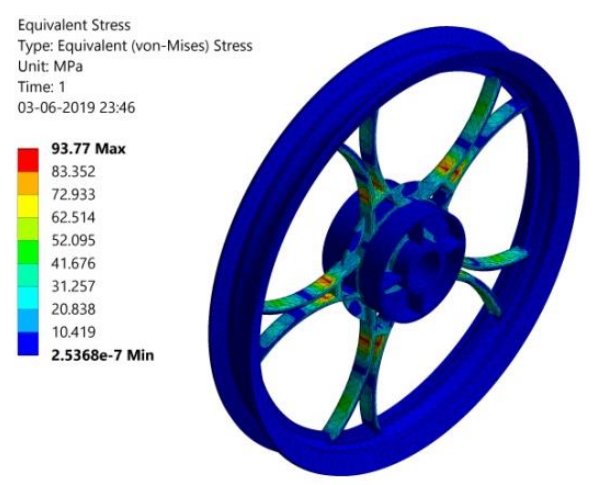

Figure. 27. Vonmises Stresses for Model 2 under torsion load case

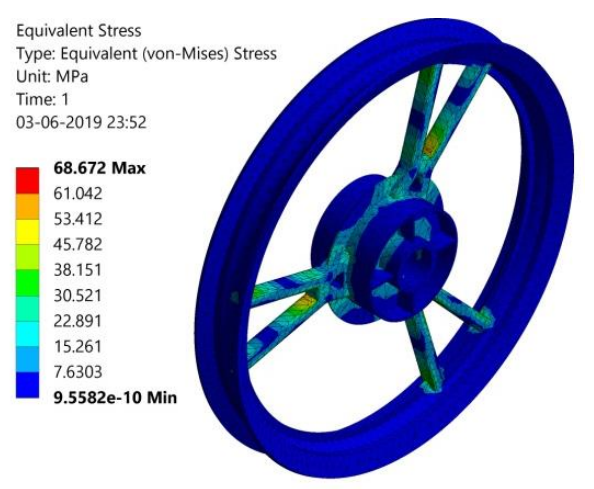

Figure. 28. Vonmises Stresses for Model 3 under torsion load case

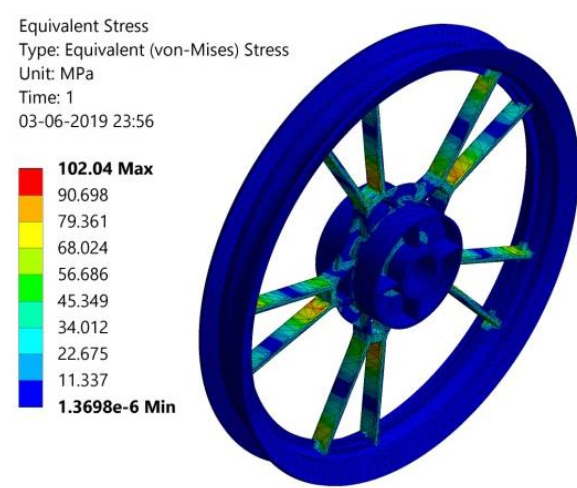

Figure. 29. Vonmises Stresses for Model 4 under torsion load case

From the above figures, the maximum stress value of the four different alloy wheel models is $102.04 \mathrm{MPa}$ developed in the model 4.

The life cycles of the model 4 is calculated from the below equation.

$$
\begin{gathered}
\log \sigma=\mathrm{A} \log \mathrm{N}+\mathrm{B} \\
\log 102.04=-0.1096 \log \mathrm{N}+2.79475 \\
2.0087=-0.1096 \log \mathrm{N}+2.79475 \\
2.0087-2.79475=-0.1096 \log \mathrm{N} \\
-0.7859=-0.1096 \log \mathrm{N} \\
7.1713=\log \mathrm{N} \\
\mathrm{N}=14837006 \text { Cycles }
\end{gathered}
$$

It clearly shows that the life cycle of the model 4 greater than the 100000 cycles. It implies the remaining models which are below the stress value of model 4 are also experience more than 100000 life cycles.

\section{Deflection Load Case}

In the maximum deflection load case, the maximum deflection of the alloy wheel should be less than the $15 \mathrm{~mm}$ as shown in the table 2.0. The calculated maximum deflection of the alloy wheel is shown in the below figure.

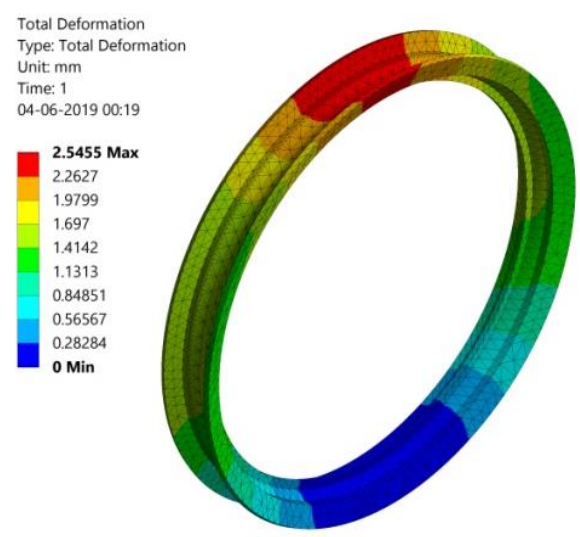

Figure. 30. Total Deformation of the wheel rim under maximum deflection load case

From the above figure, the maximum deflection of the alloy wheel model is $2.5455 \mathrm{~mm}$. It clearly shows that the maximum deflection of the alloy wheel rim is less than the safe limit [ $25 \mathrm{~mm}$ ] which is shown in the table 2 . So the rim of the alloy wheel model is safe in stiffness point of view. 


\section{CONCLUSIONS}

The four different alloy wheels are designed as per the dimensions and analyzed under five different loading conditions. The following conclusions are drawn from the above five analysis.

1. Radial Load Case

The stresses induced in the four different alloy wheels are less than the endurance limit of the material which indicates that the four models experience infinite life cycles.

2. Impact Load Case

The stresses induced in the four different alloy wheel models are less than the yield strength of the material. Indicates the four alloy wheel models are safe in strength point of view.

3. Bending load case

The calculated life cycles of the four different alloy wheel models under bending load case are greater than the 100000 life cycles.

4. Torsion Load Case

The calculated life cycles of the four different alloy wheel models under torsion load case are greater than the 100000 life cycles.

5. Maximum Deflection load case

The maximum deflection of the alloy wheel is less than the safe limit which is mentioned by the AIS.

From the above conclusions, the four different alloy wheel models are safe in all loading conditions.

\section{REFERENCES}

1. Navuri Karteek, B. Satya Krishna, B. Kiran Babu and Beulah Mani Paleti. International Journal of Innovative Technology and Exploring Engineering, 8, 702 (2019).

2. Shantaram Jashav and Gyanendra Roy, "Structural Analysis of spoke wheel rim assembly of Motorcycle", Altair Technology Conference, India (2015).

3. Sahil Bandral and satnam Singh, International Journal of Engineering research \&Technology, 6, (2018).

4. Anusha. R and Tara Sasanka. C, International Journal of Innovative Research in science, Engineering and Technology, 8, 15328 (2017).

5. Shwetabh Suman, J. Abhimanyu abrol and K Ravi, IOP Conference series: Materials Science and engineering 263, 062074 (2017).

6. G. V. R. Seshagiri rao, Akashdeep Gupta, B. Prasanth and D. V. Ramana Reddy, International journal of Mechanical Engineering and Technology, 8, 889 (2017).

7. Eswara Kumar A, Nagaraju M, N Karteek and D Prakash, Applied Mechanics and Materials, 813, 915 (2015).

8. AIS-073 (Part 1). Automotive Vehicles - Wheel Rims for Two and Three Wheeled Vehicles -Light Alloy Wheel Rims -Methods of Test and Requirements.

9. Standard Practices for Cycle Counting in Fatigue Analysis, American society for testing and materials. ASTM E 1049 - 85 ( reapproved 1997).

10.Ali Fatemi, Fatigue from variable amplitude loading, chapter 9 Variable amplitude loading, university of Toledo.

11.Fatigue Analysis in ANSYS by CAE Associates.

12.Yung-Li Lee and Ta na Tjhung, Rainflow Cycle Counting Techniques, Chapter 3.
13.Tom Irvine, Rainflow Cycle Counting in Fatigue Analysis, Revision A, (2011).

14. Tom Irvine, Rainflow Cycle Counting in Fatigue Analysis, Revision B, (2018).

15.Tom Irvine, Miner's Cumulative Damage Via Rainflow Cycle Counting, Revision G (2014).

16.Mary M Doyle, "The Design of an aluminium alloy wheel using three dimensional Finite Element Analysis and Fatigue Life Prediction". Thesis Submitted to Dublin City University.

17.John Waegter, Stress range histories and rain flow counting (2009).

18. http://www.vibrationdata.com/ 